\title{
What is the appropriate sample size for strike and dip measurements? An evaluation from compass, smartphone and LiDAR measurements
}

\author{
Cicilie Trede', Nestor Cardozo' \& Lisa Watson' \\ ${ }^{1}$ Department of Energy Resources, University of Stavanger, 4036 Stavanger, Norway. \\ E-mail corresponding author (Nestor Cardozo): nestor.cardozo@uis.no
}

Geological planar surfaces are irregular and therefore, an important question is: what is the appropriate sample size for measuring their orientations? We explore this question by measuring the orientation of two metre-sized surfaces, a shallow foliation in an overhang and a more irregular steep joint plane, in Cambro-Ordovician mica schists of the Svarthola cave, Rogaland, SW Norway. We use three methods: a geological compass; smartphones with digital compass clinometer applications, i.e., Stereonet Mobile (iPhone) and Fieldmove Clino (iPhone and Android); and LiDAR scans of increasing resolution. While geological compass measurements are generally robust, they provide inaccurate measurements in the challenging foliation overhang. Stereonet Mobile measurements are more accurate, while Fieldmove Clino is reliable in the iPhone but not in the Android device. Mean surface orientations reach a consistent result after 100-150 smartphone measurements. However, neither the compass nor the smartphone measurements can clearly define the joint-surface orientation. Triangulated surfaces from the LiDAR scans deliver precise but inconsistent results, especially at the highest resolution in the joint plane. Kriging of the surfaces significantly improves the representativeness of the computed orientations to reflect a more realistic model. A best-fit to plane routine using points within a radius, $r$, delivers the most representative results. At $r \sim 0.5 \mathrm{~m}$, the estimated orientations stabilise, and all scans deliver similar results. This is the appropriate sample size for measuring the studied planes. Similar strategies should be taken into consideration when measuring planes in outcrop (sighting as opposed to direct measurement) or from 3D geological models.

Keywords: Strike and dip, compass, smartphones, LiDAR, best-fit plane, sample size

Received 30. January 2019 / Accepted 11. June 2019 / Published online 10. September 2019

\section{Introduction}

Smartphones, small unmanned aerial vehicles (UAVs), Structure from Motion (SfM) photogrammetry, and light detection and ranging (LiDAR) have revolutionised the way we collect structural measurements in the field. Smartphones enable rapid collection of measurements, allowing for data redundancy and uncertainty estimates (Allmendinger et al., 2017). The accuracy of Android devices, however, has been questioned, mostly in relation to the low reliability of the device magnetometer (Lee et al., 2013; Novakova \& Pavlis, 2017). iOS devices, on the other hand, seem to be reliable for all but the most demanding applications, provided care is taken with respect to objects that could affect the magnetic field (Allmendinger et al., 2017). SfM and LiDAR virtual outcrop models provide an exceptional 3D view of structures, as well as the chance to extract a wealth of structural measurements consistent with both compass and smartphone measurements (Cawood et al., 2017). UAV-based SfM models may be less accurate than LiDAR, but they can have greater coverage and contribute to a better characterisation of the structures (Cawood et al., 2017).

Trede, C., Cardozo, N. \& Watson, L. 2019: What is the appropriate sample size for strike and dip measurements? An evaluation from compass, smartphone and LiDAR measurements. Norwegian Journal of Geology 99, 1-14. https://dx.doi.org/10.17850/njg99-3-4. 
When determining the orientation of planar surfaces in the field, from virtual outcrop models, or even subsurface geological models derived from seismic and well data, there are three main aspects to keep in mind: plane orientation, surface roughness and measuring device adaptability to the surface. Each of these aspects has associated methodological and conceptual considerations. For plane orientation, considerations include: What is the 'correct' orientation of a planar feature; how do we define a correct orientation; and does it depend on the scale of observation? For example, someone studying asperities on a fault surface would define the correct orientation very differently than someone using orientation to determine the intersection of a fault with a reservoir unit in a 3D seismic cube (Yielding \& Freeman, 2016). Considerations related to surface roughness are: natural surfaces are inherently irregular; how does surface roughness affect the question of how big an area is needed to sample in order to get an accurate measurement; what is the best way to characterise surface roughness (LiDAR?); and how does roughness vary with lithology and structure type (bedding, faults, joints, etc.)? Finally, determining measuring-device adaptability to a unique surface requires forethought and considers the following: how do standard tools (e.g., compass and mobile devices) and more advanced tools (e.g., virtual outcrop models) cope with surface roughness; what are the most efficient strategies for obtaining the most accurate measurement(s) from these tools; and what is the probability that a randomly placed compass/smartphone or a randomly chosen area from a virtual outcrop model would yield a similar result on a surface of a particular roughness?

In this short note, we explore measuring-device adaptability to a surface by studying two different metresized surfaces, a shallow foliation and a steep joint plane, in Cambro-Ordovician mica schists of the Buadalen nappe at the Svarthola cave, Rogaland, SW Norway (Slama \& Pedersen, 2015). We scanned the surfaces with LiDAR at different frequencies and resolutions, and compared the strike and dip measurements from the LiDAR scans to those from a geological compass, iPhone and Android device on the same surfaces. Overall, the results indicate that the minimum size to correctly characterise the foliation and joint is $\sim 0.5 \mathrm{~m}$, regardless of the measuring device, which suggests that sighting measurements from this distance are more correct than direct measurements on these planes.

\section{Case study}

The study area is a prehistoric cave called Vistehola or Svarthola (the black cave), in Randaberg municipality, northwest of Stavanger, Norway (Fig. 1A). The cave was inhabited in the Stone Age ( 6000 BC) when it was near sea level. Today, it is $\sim 16 \mathrm{~m}$ above sea level, marking the marine limit at this location (Riis, 2016). The outcrop consists of Cambro-Ordovician quartz-rich phyllite to mica schist, relatively dark in colour (Fig. 1A-B; Geological Survey of Norway 1:250,000 geological map and Ramberg et al., 2008; Slama \& Pedersen, 2015). We chose two surfaces near the cave, a foliation and a steeper joint plane (Fig. 1C, surfaces I and II). The foliation is in an overhang, which makes it more difficult to measure with a compass, and the joint plane is more irregular than the foliation. Crenulation cleavage adds irregularity to both planes.

\section{Methods}

We measured the orientation of the foliation and joint surfaces using three methods: i. Brunton Geo compass, ii. digital compass clinometer applications on smartphone devices, and iii. LiDAR scans. About 30 strike and dip measurements were collected on each plane using the Brunton Geo compass. For the smartphone devices, we used two applications: Stereonet Mobile (Allmendinger et al., 2017) and Fieldmove Clino (Midland Valley). Stereonet Mobile is an iOS application, while Fieldmove Clino has both iOS and Android versions. We tested these applications on an iPhone 6 (Stereonet Mobile and Fieldmove Clino) and on a Samsung A3 Android device (Fieldmove Clino). For Stereonet Mobile, it is important to note that the program handles transients in the sensor data by redundant sampling (10 measurements per second after the device has been held stable for 1 second; Allmendinger et al., 2017). Thus, every measurement in Stereonet Mobile is the average of tens of measurements. For Fieldmove Clino, it is not clear what the background measurement strategy is, although in iOS both Stereonet Mobile and Fieldmove Clino seem to be comparable, probably because they use the same iOS routines (Allmendinger et al., 2017). On each plane, and using both the iPhone and Android devices, 200 strike and dip measurements were collected.

The use of LiDAR data (3D point clouds) for extracting discontinuity (planar surfaces) orientations has been a subject of research for the last twenty years. The initial use of triangulated surfaces (e.g., Feng et al., 2001) has been superseded by more advanced techniques, including automatic algorithms for point cloud classification into discontinuity sets using clustering analysis, region growing and kernel density estimation (KDE; Gigli \& Casagli, 2011; Riquelme et al., 2014; Guo et al., 2017; Thiele et al., 2017). Although today these techniques are almost the standard for measuring discontinuities from LiDAR data, the purpose of this note is not to look at the application of these techniques, but rather at the impact of applying different sampling strategies to the LiDAR 

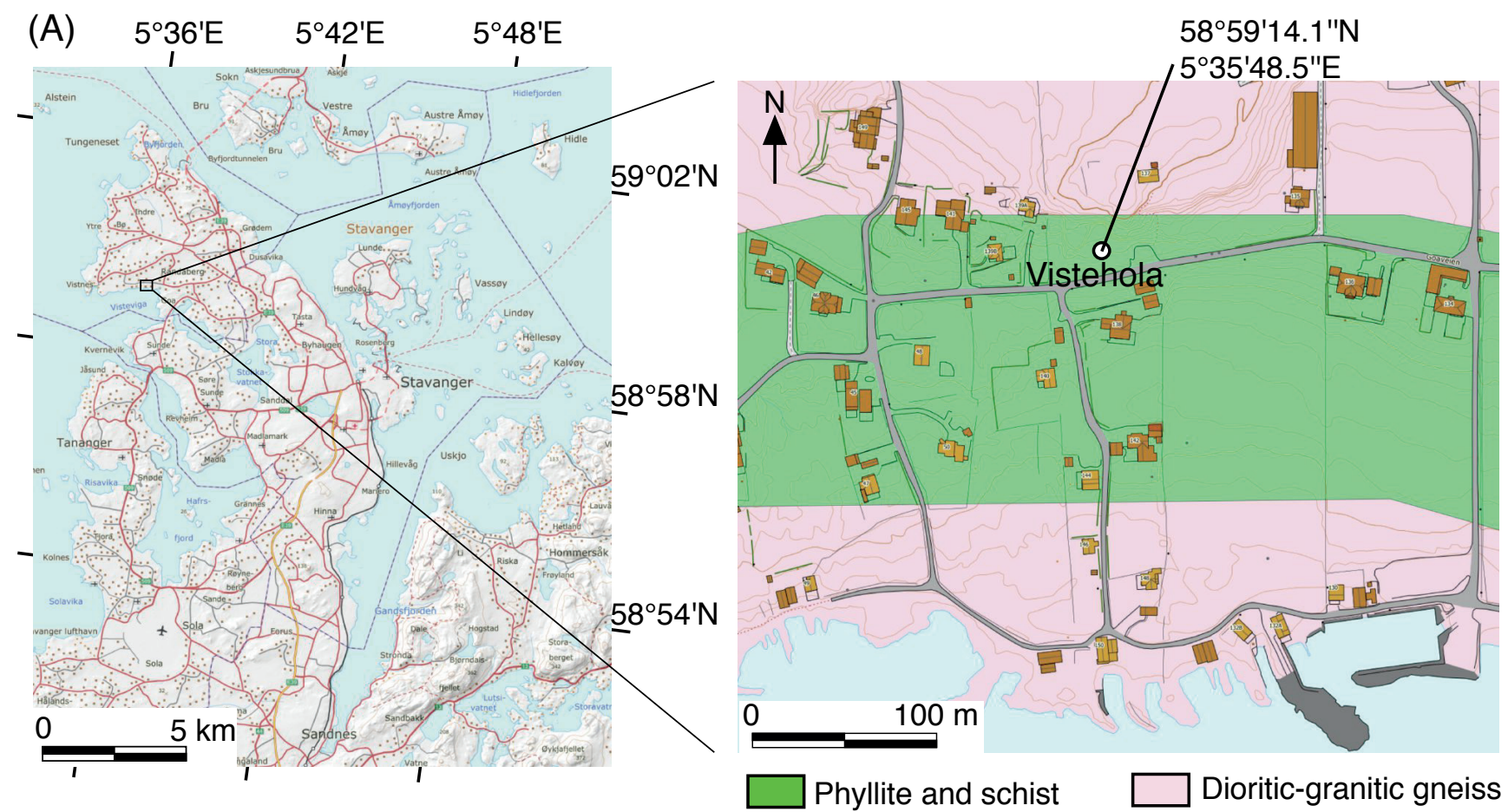

(B)

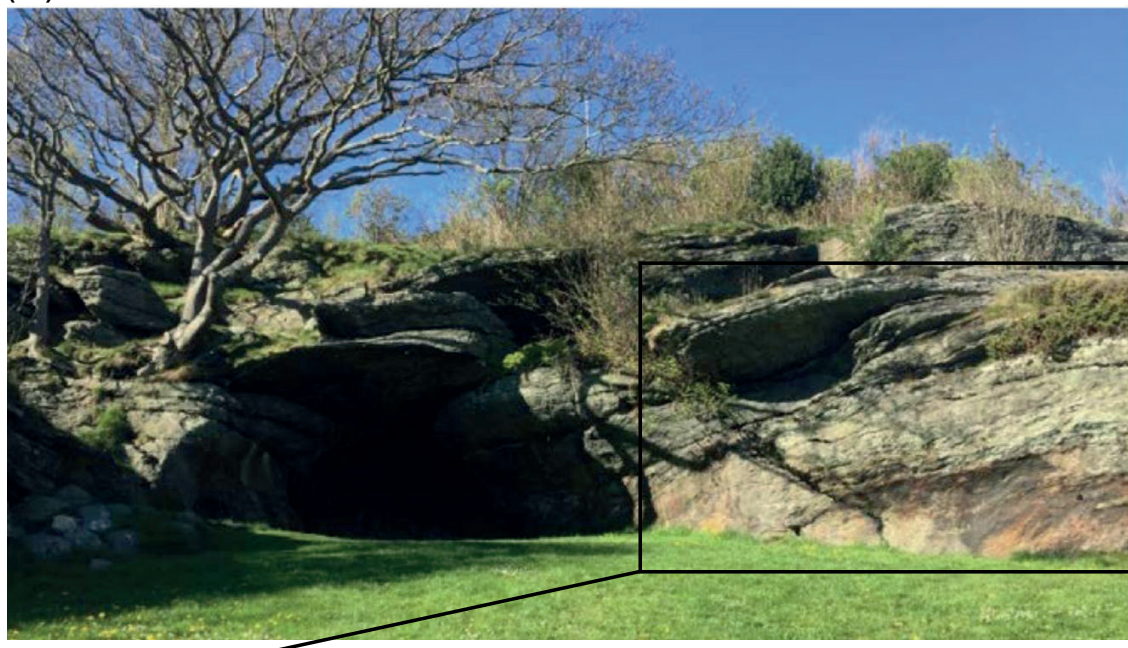

(C)

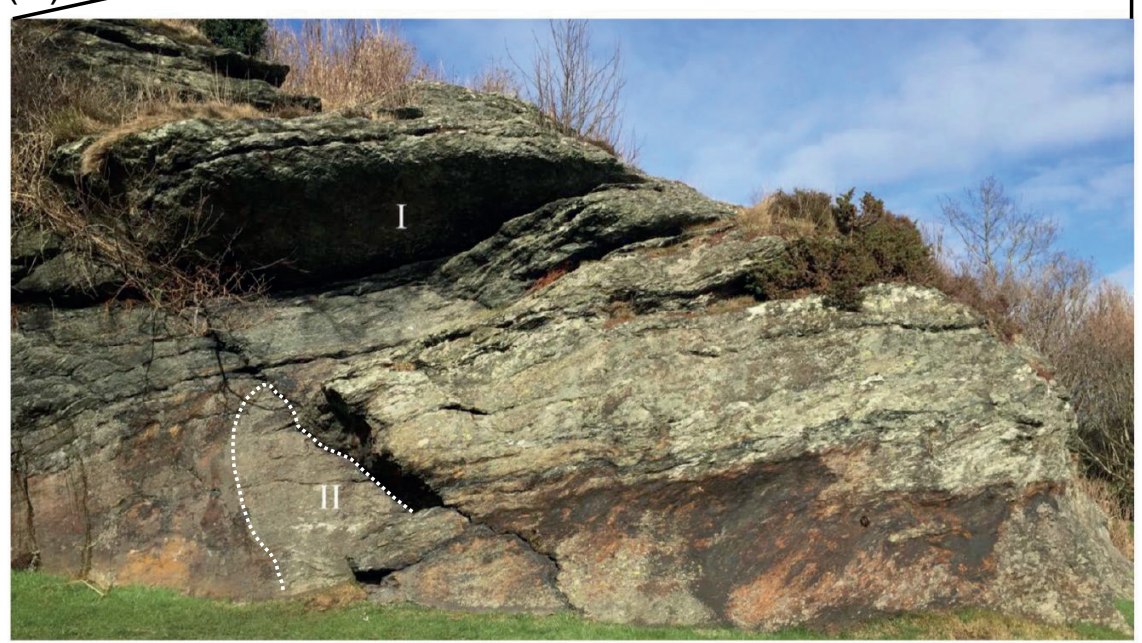

Figure 1. (A) Vistehola location with zoom of local area. Maps from the Geological Survey of Norway (NGU) server. (B) Photograph of the cave. (C) Photograph of foliation (I) and joint (II) surfaces. 
Table 1. Five LiDAR scans with frequency and point spacing.

\begin{tabular}{cccc}
\hline Scan $(\mathrm{kHz})$ & Vertical Point Spacing $(\mathrm{m})$ & Horizontal Point Spacing $(\mathrm{m})$ & Phi $($ deg. $)$ \\
\hline 30 & 0.023 & 0.094 & 0.5 \\
30 & 0.022 & 0.044 & 0.2 \\
30 & 0.021 & 0.02 & 0.1 \\
150 & 0.016 & 0.019 & 0.1 \\
300 & 0.013 & 0.022 & 0.05 \\
\hline
\end{tabular}

data, from the crudest one (Delaunay triangulation) to more inclusive gridding (Kriging and best-fit-toplane) routines; this is completed with the objective of establishing the right sample size for determining the orientation of the scanned surfaces.

LiDAR scans of the cave were obtained with a Riegl VZ-4000 instrument from a distance of $2.6 \mathrm{~m}$. Five scans were shot from the same position but with different frequencies and resolution point spacings (Table 1). These data were collected in the winter when there was less vegetation. The LiDAR point clouds were imported into RiSCAN Pro (RIEGL) where areas of high vegetation were removed. As an example, Fig. 2 shows the LiDAR model for the $150 \mathrm{kHz}$ scan after vegetation removal and additional processing steps including triangulation, smoothing, decimation and texturising (Hodgetts, 2013). The LiDAR point clouds were imported into Move (Midland Valley), where the foliation and joint surfaces (I and II in Fig. 2) were isolated, and surface orientation analysis and gridding routines were performed.

\section{Results}

\section{Compass}

Twenty-seven measurements were taken on the foliation and 30 measurements on the joint plane. The strike and dip distribution of these measurements is shown in Fig. 3A. The foliation measurements show more spread in strike than those of the joint plane, perhaps because the foliation is located in an overhang and is more difficult to measure (Fig. 2). The spread in the strike measurements of both planes, however, is relatively low, which confirms the benefit of using a geological compass with a good damping mechanism such as the Brunton Geo compass. The dip measurements of both planes show a higher spread. In the foliation, this is due to the difficulties of measuring, and in the joint plane this is more inherent to the irregularity of the plane. The mean vector of the poles to the foliation is $197 / 73$ and of the poles to the joint plane $027 / 10$ (Fig. 4). For both planes, the 95\%

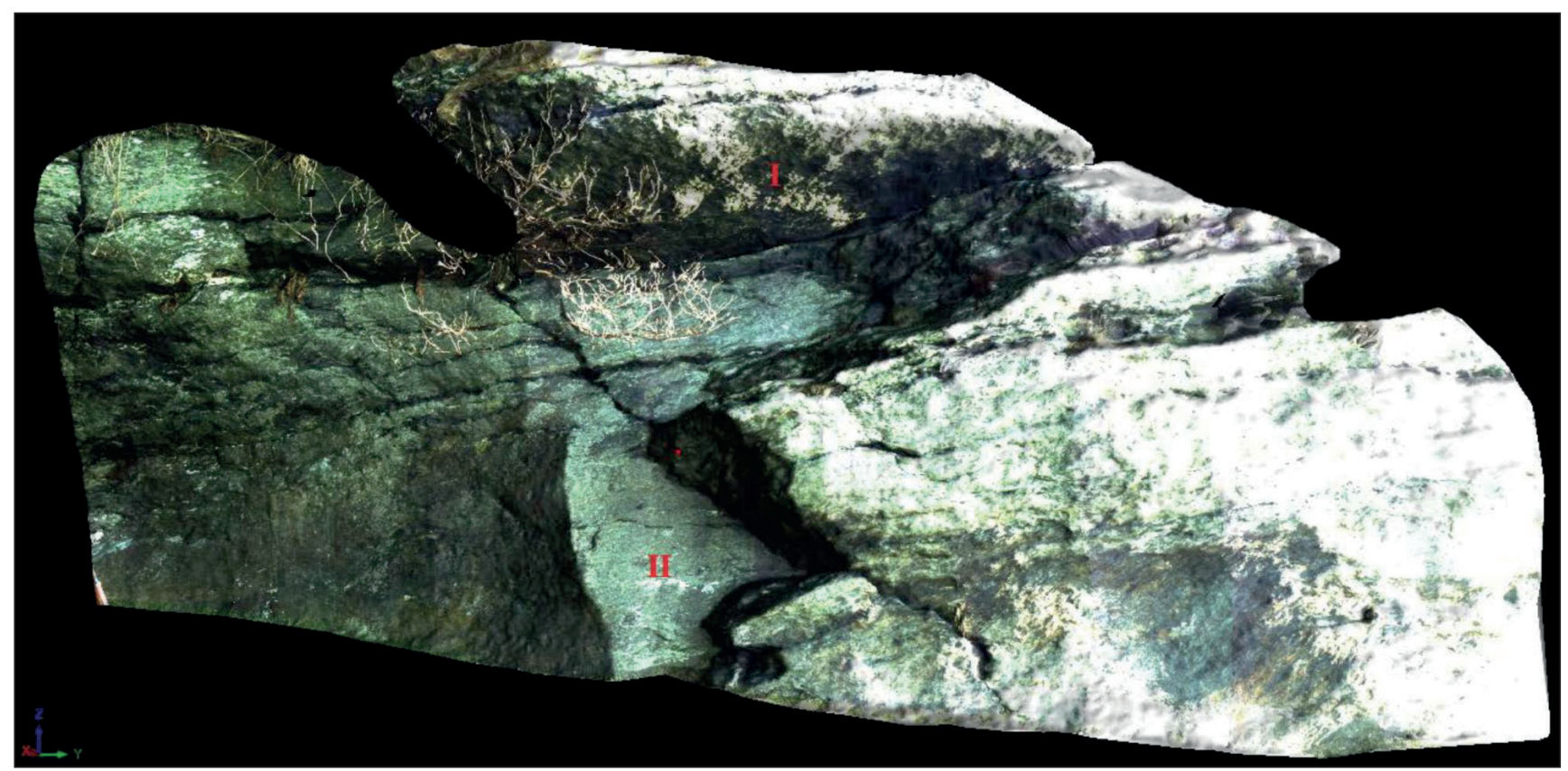

Figure 2. Virtual outcrop model of the cave from the LiDAR $150 \mathrm{kHz}$ scan. Surfaces I and II are the foliation and joint plane, respectively. 
confidence cone (or error) of the mean vector calculation (Fisher et al., 1987; Allmendinger et al., 2012) is $\sim 2^{\circ}$ (Table 2).

\section{Smartphone applications}

Fig. 3B-D show the strike and dip histograms of the foliation and joint measurements from the three smartphone applications, coloured by the first 50 (black), 100 (dark grey), 150 (light grey), and 200 (white) measurements. While the overall distribution of these measurements is similar and matches the compass measurements, close inspection shows that there are differences between the three applications. For the foliation, the Stereonet Mobile measurements (Fig. 3B) have less spread in strike than the iPhone and Android Fieldmove Clino measurements (Fig. 3C-D), while for the joint plane, the iPhone Fieldmove Clino measurements (Fig. 3C) have less spread in strike than the Stereonet Mobile and Android Fieldmove Clino measurements (Fig. 3B \& D). For both planes, the three applications show similar spread in dip.

However, as Allmendinger et al. (2017) demonstrate, comparing separate strike or dip readings is misleading and one should rather compare the complete strike and dip orientation of the plane. Fig. 4 shows the mean vectors and $95 \%$ confidence cones of the poles to the foliation and joint surfaces from the smartphone applications, again separated for the first 50, 100, 150 and 200 measurements. These results are also included in Table 2. For the foliation, the Stereonet Mobile application provides the most consistent results delivering mean vector orientation $(\sim 177 / 72)$ with the lowest dispersion (compared to the compass and the other two smartphone applications) from
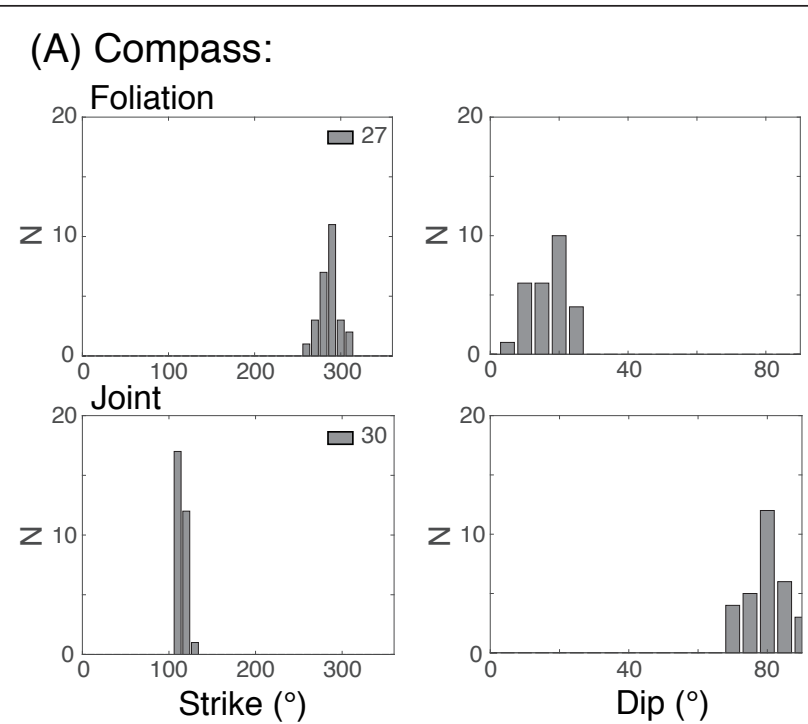

(C) iPhone Fieldmove Clino:
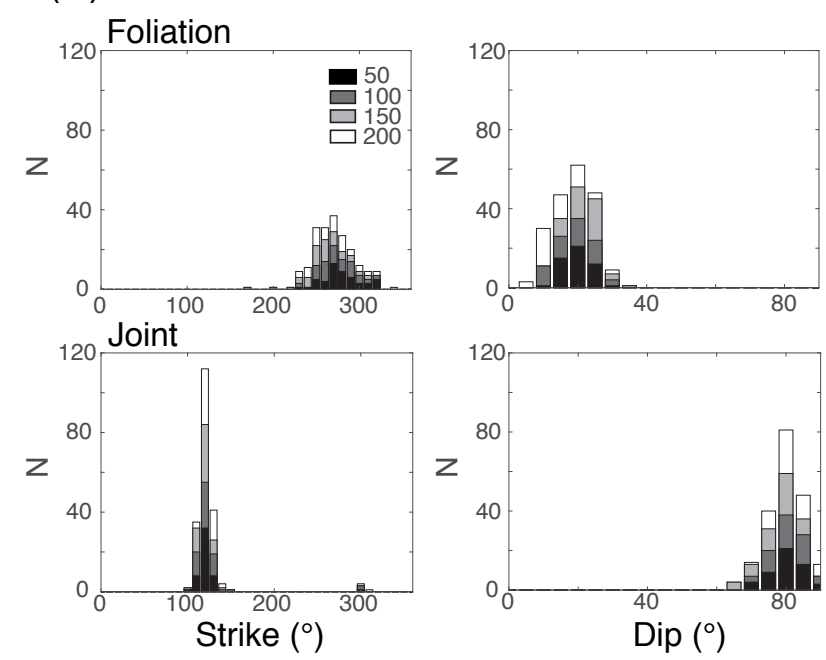

(B) iPhone Stereonet Mobile:
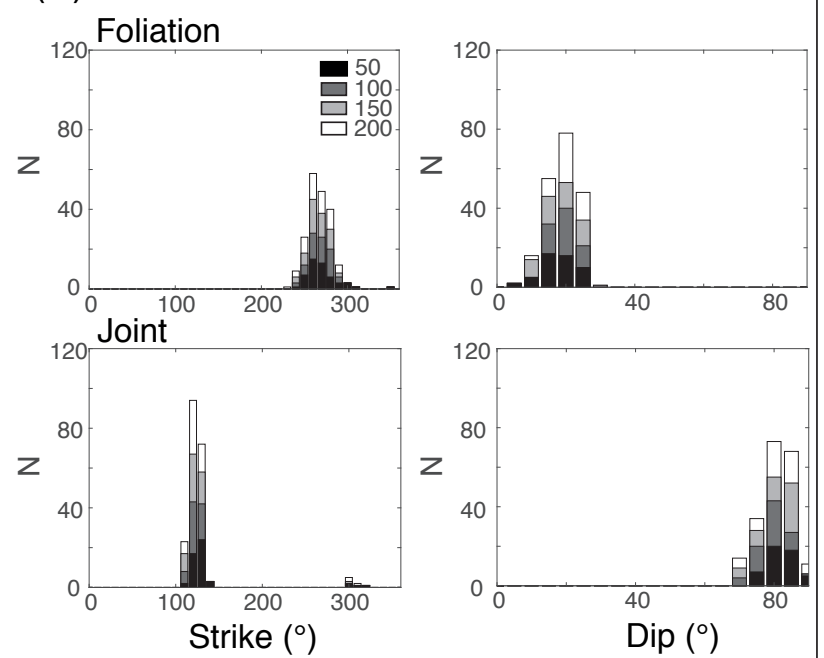

\section{(D) Android Fieldmove Clino:}
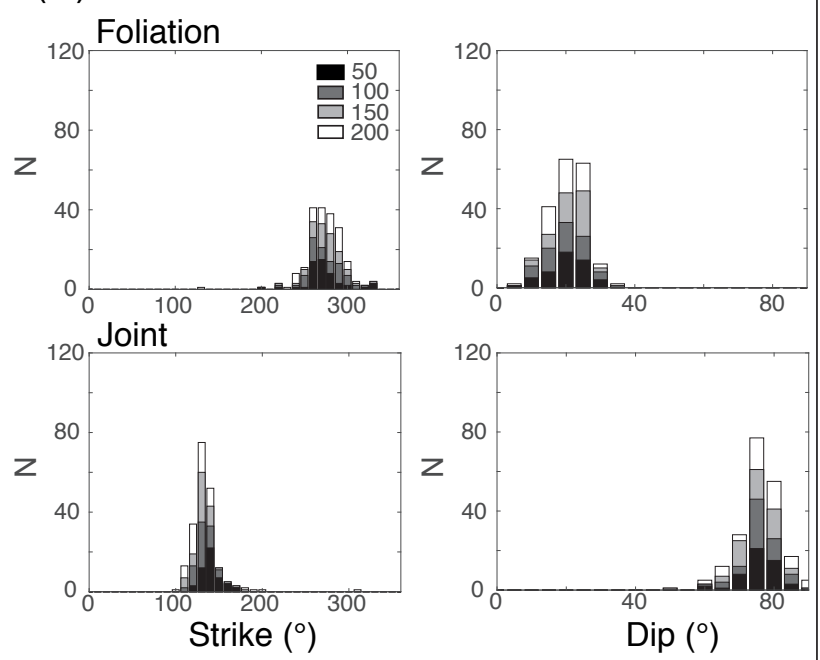

Figure 3. Strike and dip histograms of the foliation and joint measurements from (A) Geological compass, (B) iPhone Stereonet Mobile, (C) iPhone Fieldmove Clino, and (D) Android Fieldmove Clino. For the smartphone applications, stacked histograms are shown for the first 50 (black), 100 (light grey), 150 (dark grey), and 200 (white) measurements. 

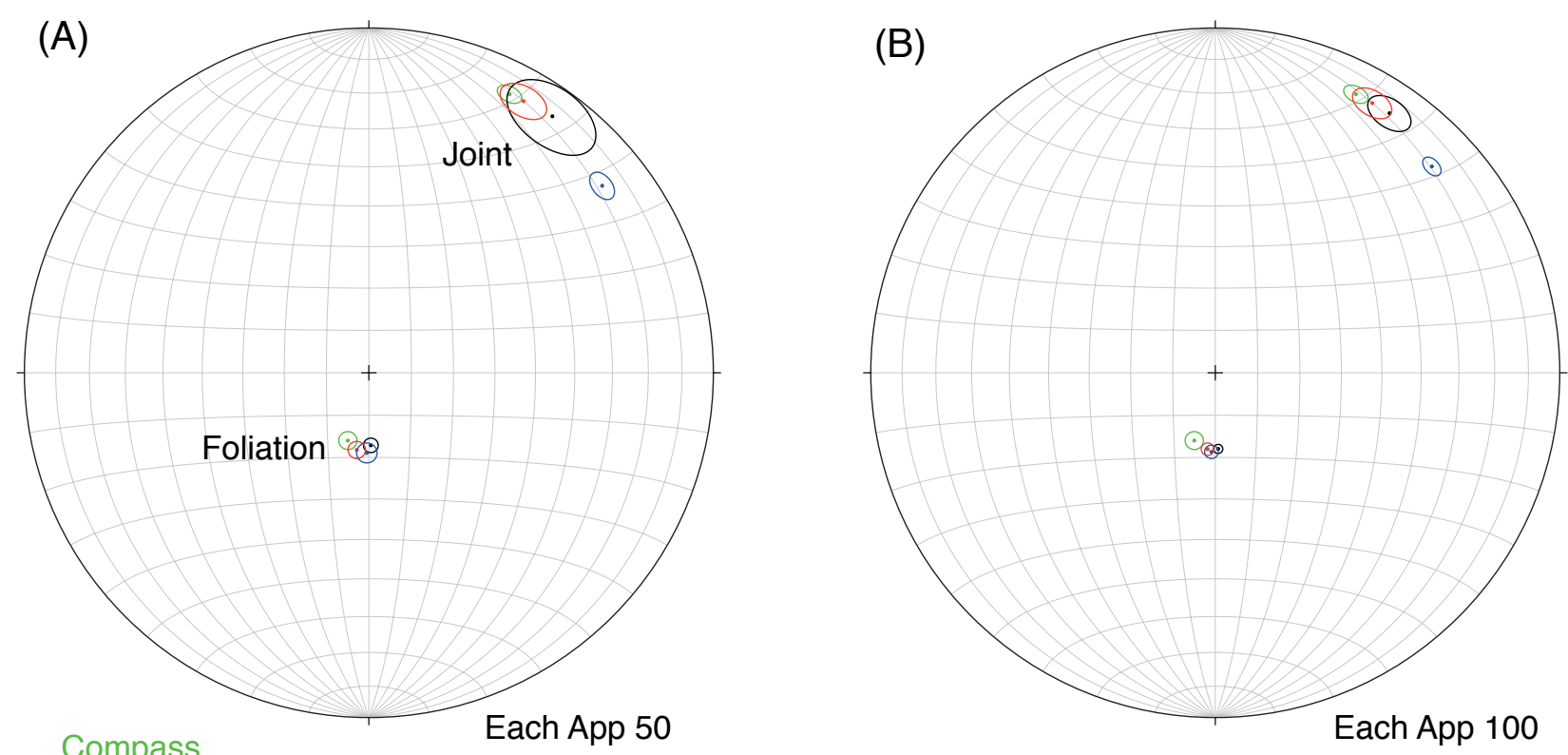

\section{iPhone Stereonet Mobile \\ iPhone Fieldmove Clino} Android Fieldmove Clino
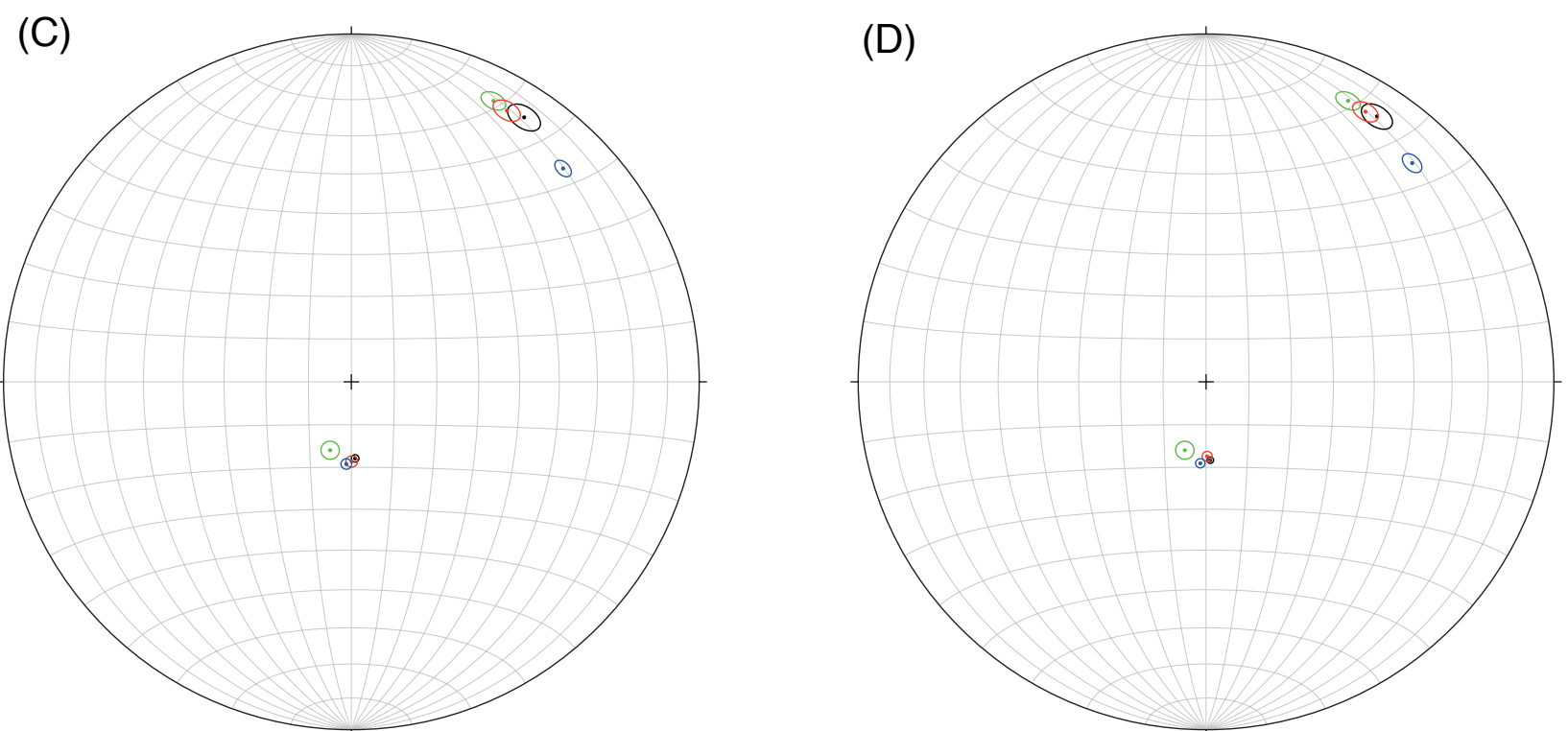

Each App 150

Each App 200

Figure 4. Lower hemisphere, equal-area stereonets showing mean vectors of the poles to the foliation and joint surfaces for the compass (green), iPhone Stereonet Mobile (black), iPhone Fieldmove Clino (red) and Android Fieldmove Clino (blue) measurements. Mean vectors are shown for the first (A) 50, (B) 100, (C) 150 and (D) 200 smartphone measurements. Small circles indicate 95\% confidence cones.

the first 50 to the last 200 measurements (Fig. 4; Table 2). The Fieldmove Clino application in both the iPhone and the Android devices delivers less consistent results with more variation (Fig. 4; Table 2). It is interesting to note that the mean vector from the compass measurements has a different trend (197) than the mean vectors of the smartphone applications ( 180; Fig. 4; Table 2). This can be explained by the difficulty of measuring the foliation in an overhang with the compass, while the smartphone readings on the same plane are easier to take and they appear more accurate.
For the joint plane, Stereonet Mobile also delivers consistent results, although the mean vector for the first 50 measurements shows a high variation (Fig. 4A), which decreases as more measurements are taken (Fig. 4B-D; Table 2). This can be explained by the irregularity of the plane, which has greater influence over the mean vector calculation in the first 50 measurements than when more measurements are taken and the influence of dissimilar orientations is smoothed out (Fig. 3B). Fieldmove Clino in the iPhone device delivers a similar mean vector with somewhat more consistency (Fig. 4; Table 2). However, 
Table 2. Mean vectors of poles to the foliation and joint surfaces from compass and smartphone measurements.

\begin{tabular}{|c|c|c|c|c|c|}
\hline Method & Plane & $N$ & Trend (deg.) & Plunge (deg.) & 95\% confidence cone (deg.) \\
\hline \multirow[t]{2}{*}{ Compass } & Foliation & 27 & 197 & 73 & 2.12 \\
\hline & Joint & 30 & 027 & 10 & 2.38 \\
\hline \multirow[t]{8}{*}{ Stereonet Mobile } & Foliation & 50 & 178 & 73 & 1.71 \\
\hline & & 100 & 178 & 72 & 1.08 \\
\hline & & 150 & 177 & 72 & 0.87 \\
\hline & & 200 & 177 & 72 & 0.76 \\
\hline & Joint & 50 & 036 & 9 & 9.06 \\
\hline & & 100 & 034 & 10 & 4.37 \\
\hline & & 150 & 033 & 10 & 3.27 \\
\hline & & 200 & 033 & 10 & 3.09 \\
\hline \multirow[t]{8}{*}{ iPhone FieldMove Clino } & Foliation & 50 & 189 & 72 & 2.03 \\
\hline & & 100 & 186 & 72 & 1.48 \\
\hline & & 150 & 180 & 71 & 1.34 \\
\hline & & 200 & 179 & 73 & 1.16 \\
\hline & Joint & 50 & 030 & 10 & 4.59 \\
\hline & & 100 & 030 & 10 & 3.88 \\
\hline & & 150 & 030 & 11 & 2.68 \\
\hline & & 200 & 031 & 11 & 2.53 \\
\hline \multirow[t]{8}{*}{ Android FieldMove Clino } & Foliation & 50 & 182 & 71 & 2.37 \\
\hline & & 100 & 183 & 71 & 1.59 \\
\hline & & 150 & 184 & 71 & 1.24 \\
\hline & & 200 & 184 & 71 & 1.09 \\
\hline & Joint & 50 & 051 & 14 & 2.92 \\
\hline & & 100 & 046 & 14 & 2.07 \\
\hline & & 150 & 045 & 15 & 1.83 \\
\hline & & 200 & 043 & 15 & 2.12 \\
\hline
\end{tabular}

$\mathrm{N}$ - number of measurements.

the same application in the Android device delivers a mean vector dissimilar to the compass and the iPhone mean vectors (Fig. 4; Table 2). This suggests that there is a problem with the device, most probably with its magnetometer (Novakova \& Pavlis, 2017). Although we are not certain why this error is larger in the joint plane, perhaps it is because this plane was closer to nearby metallic objects on the ground (hammers, keys, thermos bottles, etc.). For both the foliation and the joint surfaces and for the three smartphone applications, the estimated mean vectors do not change much after 150 measurements (Fig. 4C-D; Table 2), which implies that 100-150 smartphone measurements are enough to characterise the planes.

\section{LiDAR}

The simplest way to construct a surface from a point cloud in terms of ease of use, straightforward methodology, and least taxing computation is through Delaunay triangulation. Fig. 5 shows the Delaunay triangulated foliation and joint surfaces from the LiDAR point clouds from the lowest resolution (less dense; Fig. 5A) to the highest resolution (more dense; Fig 5E) scans (Table 1). The surfaces are coloured by the strike (first column, Fig. 5) and dip (second column, Fig. 5) of the triangular facets, and the distribution of these measurements is included in the last column of Fig. 5. The overall pattern of the strike and dip histograms for the foliation and joint surfaces are similar regardless of the frequency or resolution of the scan. However, as the resolution increases and more smaller-scale facets are included, the spread of the strike and dip measurements increases (Fig. 5). At the highest resolution (Fig. 5E), it is actually difficult to discern the predominant strike and dip orientations. In terms of the mean vector of the poles to the facets, increasing resolution has little effect on the mean vector for the foliation ( 190/71; Fig. 6A; Table $3)$. However, for the more irregular joint plane, which has a bimodal strike distribution (Fig. 5, last column), increasing resolution results in greater differences from the mean vector of the compass measurements (Fig. 6A). In addition, this mean vector has a normalised length that 


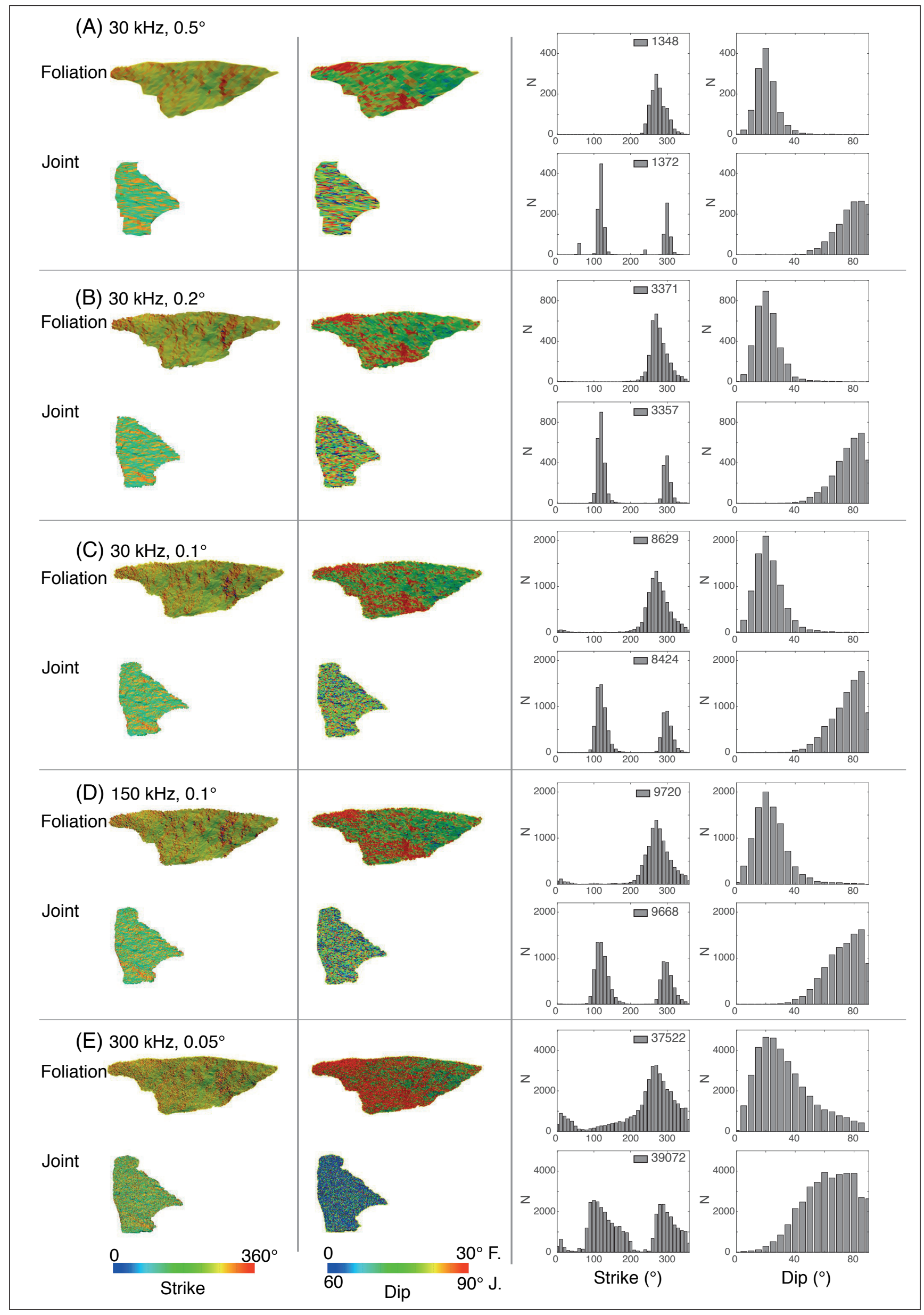


Figure 5. Delaunay triangulated foliation and joint surfaces from the LiDAR (A) $30 \mathrm{kHz}, 0.5^{\circ}$, (B) $30 \mathrm{kHz}, 0.2^{\circ}$, (C) $30 \mathrm{kHz}, 0.1^{\circ}$, (D) 150 $\mathrm{kHz}, 0.1^{\circ}$ and (E) $300 \mathrm{kHz}, 0.05^{\circ}$ scans. The first column shows surfaces coloured by strike, second column shows surfaces coloured by dip, and third column shows the surfaces' strike and dip histograms. Notice that in the second column, the surfaces are coloured with different dip ranges. The foliation is coloured using a $0-30^{\circ}$ dip range, while the joint is coloured using a $60-90^{\circ}$ dip range. The number of measurements is included in the strike histograms. is below the threshold for computing confidence cones (Table 3; Fisher et al., 1987). At the highest resolution, the mean vector erroneously suggests that the joint plane is subhorizontal! Thus, adding more points (and smaller facets) to the calculation does not clarify the results, but on the contrary, it magnifies surface variability, especially if the plane is irregular.

A more realistic and computationally effective way to handle the LiDAR point clouds is through Kriging (Clark \& Harper, 2000) to a grid of regular quadrilaterals. Fig. 7 shows the Kriged foliation and joint surfaces from the LiDAR point clouds from the lowest (Fig. 7A) to the highest (Fig. 7E) resolution scans. The foliation surfaces have $30 \times 30$ cells, each one with along-strike

\section{(A) Delaunay}

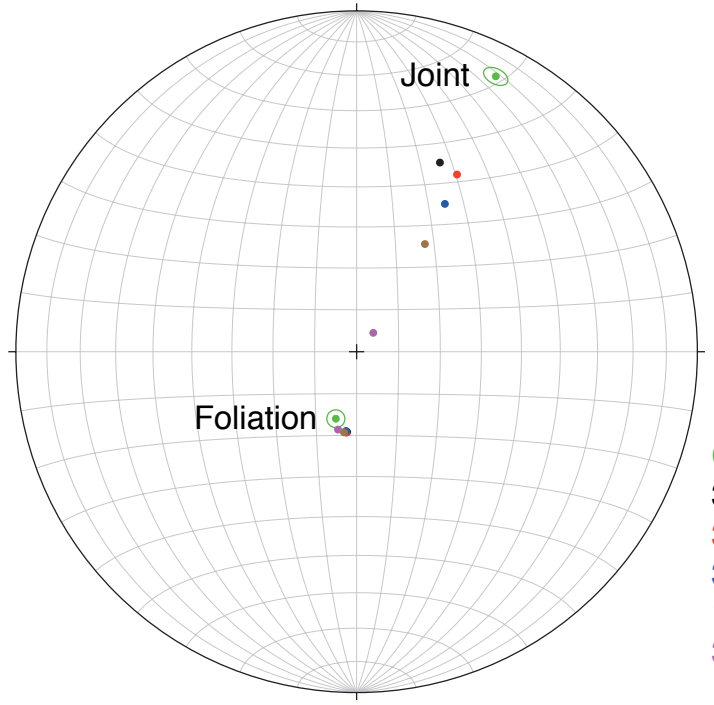

(B) Kriging

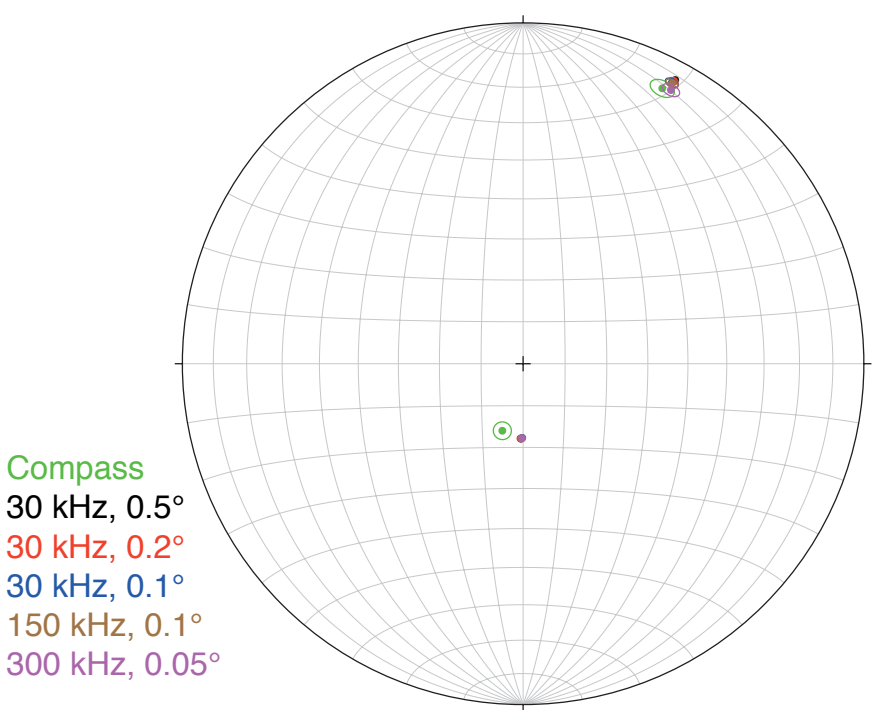

$300 \mathrm{kHz}, 0.05^{\circ}$

C) Best-fit plane, $r=0.5 \mathrm{~m}$

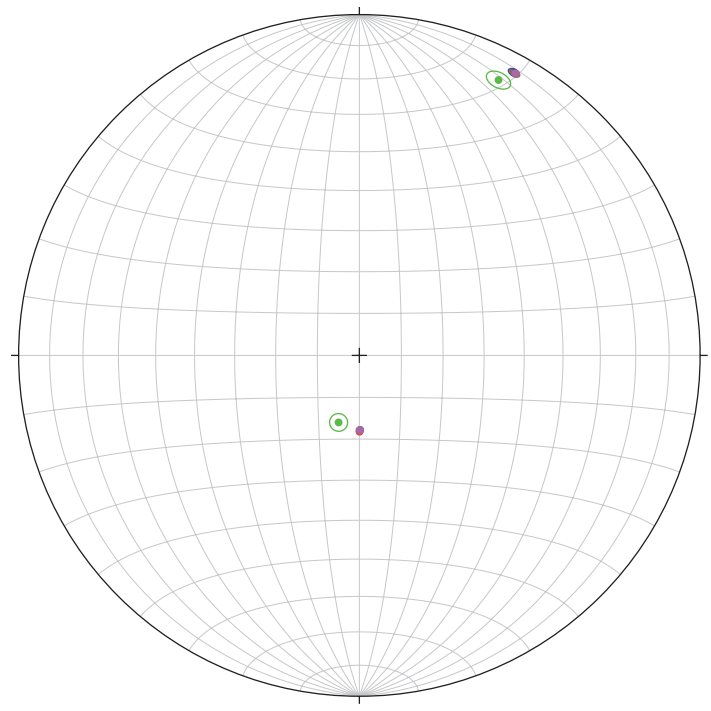

Figure 6. Lower hemisphere, equal-area stereonets showing mean vectors of the poles to the foliation and joint surfaces for the compass measurements (green), and the LiDAR scans (black to pink). (A) Delaunay triangulated surfaces (Fig. 5), (B) Kriged surfaces (Fig. 7) and (C) Best-fit to plane routine with search radius $r=0.5 \mathrm{~m}$ (Fig. 8, blue bars). Small circles indicate $95 \%$ confidence cones. 
Table 3. Mean vectors of poles to the foliation and joint surfaces from LiDAR scans.

\begin{tabular}{|c|c|c|c|c|c|c|}
\hline Method & Plane & Method & $N$ & Trend (deg.) & Plunge (deg.) & 95\% confidence cone (deg.) \\
\hline \multirow[t]{4}{*}{$30 \mathrm{kHz}, 0.5^{\circ}$} & \multirow[t]{2}{*}{ Foliation } & Delaunay & 1348 & 187 & 71 & 0.47 \\
\hline & & Kriging & 1682 & 182 & 72 & 0.26 \\
\hline & \multirow[t]{2}{*}{ Joint } & Delaunay & 1372 & 024 & 39 & * \\
\hline & & Kriging & 1610 & 028 & 6 & 0.41 \\
\hline \multirow[t]{6}{*}{$30 \mathrm{kHz}, 0.2^{\circ}$} & \multirow[t]{3}{*}{ Foliation } & Delaunay & 3371 & 187 & 71 & 0.35 \\
\hline & & Kriging & 1680 & 182 & 72 & 0.28 \\
\hline & & Best-fit plane, $r=0.5 \mathrm{~m}$ & 793 & 180 & 72 & 0.27 \\
\hline & \multirow[t]{3}{*}{ Joint } & Delaunay & 3357 & 029 & 40 & * \\
\hline & & Kriging & 1589 & 028 & 7 & 0.86 \\
\hline & & Best-fit plane, $r=0.5 \mathrm{~m}$ & 849 & 029 & 6 & 0.8 \\
\hline \multirow[t]{6}{*}{$30 \mathrm{kHz}, 0.1^{\circ}$} & \multirow[t]{3}{*}{ Foliation } & Delaunay & 8629 & 188 & 71 & 0.28 \\
\hline & & Kriging & 1682 & 181 & 72 & 0.23 \\
\hline & & Best-fit plane, $\mathrm{r}=0.5 \mathrm{~m}$ & 864 & 180 & 72 & 0.33 \\
\hline & \multirow[t]{3}{*}{ Joint } & Delaunay & 8424 & 031 & 48 & * \\
\hline & & Kriging & 1617 & 028 & 8 & 1.24 \\
\hline & & Best-fit plane, $r=0.5 \mathrm{~m}$ & 827 & 029 & 6 & 1.09 \\
\hline \multirow[t]{6}{*}{$150 \mathrm{kHz}, 0.1^{\circ}$} & \multirow[t]{3}{*}{ Foliation } & Delaunay & 9720 & 189 & 71 & 0.31 \\
\hline & & Kriging & 1682 & 181 & 72 & 0.24 \\
\hline & & Best-fit plane, $r=0.5 \mathrm{~m}$ & 821 & 180 & 72 & 0.32 \\
\hline & \multirow[t]{3}{*}{ Joint } & Delaunay & 9668 & 032 & 59 & * \\
\hline & & Kriging & 1633 & 028 & 8 & 1.19 \\
\hline & & Best-fit plane, $\mathrm{r}=0.5 \mathrm{~m}$ & 872 & 029 & 6 & 0.85 \\
\hline \multirow[t]{6}{*}{$300 \mathrm{kHz}, 0.05^{\circ}$} & \multirow[t]{3}{*}{ Foliation } & Delaunay & 37522 & 194 & 71 & 0.31 \\
\hline & & Kriging & 1682 & 181 & 72 & 0.26 \\
\hline & & Best-fit plane, $r=0.5 \mathrm{~m}$ & 874 & 180 & 72 & 0.31 \\
\hline & \multirow[t]{3}{*}{ Joint } & Delaunay & 39072 & 041 & 84 & * \\
\hline & & Kriging & 1636 & 028 & 10 & 1.71 \\
\hline & & Best-fit plane, $\mathrm{r}=0.5 \mathrm{~m}$ & 829 & 029 & 6 & 0.18 \\
\hline
\end{tabular}

$\mathrm{N}$ - number of measurements.

* - Length of mean vector normalized to 1.0 is lower than 0.65 , which is the threshold for computing confidence cones.

and dip dimensions of 12 and $6 \mathrm{~cm}$, respectively. The joint surfaces have $20 \times 20$ cells, each one with alongstrike and dip dimensions of 9 and $6 \mathrm{~cm}$, respectively. Kriging smooths the foliation and joint surfaces without removing their key irregularities to a much more reasonable cell size (in comparison to the Delaunay routine). In fact, these irregularities are better displayed in the higher resolution scans (Fig. 7E). For both planes and in all scans, the Kriged strike and dip distributions (Fig. 7, last column) and the mean vectors (Fig. 6B; Table 3 ) are consistent. Kriging greatly improves the estimation of the orientation of the planes.

The last method we tested is a best-fit to plane routine. On the foliation and joint planes, we use the points of the Kriging regular grid, and in each of these points, we estimate the plane orientation using the points in the cloud within a radius $r$. The estimation of the plane's orientation is based on a moment of inertia analysis (Fernandez, 2005; Allmendinger et al., 2012, section 5.5.2), where a minimum of 3 points is required. Fig. 8 shows the strike and dip distributions of the foliation and joint surfaces from this routine with radii 0.1 (red) to 0.9 (yellow) $\mathrm{m}$ for the four higher-resolution scans.

Figure 7. Kriged foliation and joint surfaces from the LiDAR (A) 30 $\mathrm{kHz}, 0.5^{\circ}$, (B) $30 \mathrm{kHz}, 0.2^{\circ}$, (C) $30 \mathrm{kHz}, 0.1^{\circ}$, (D) $150 \mathrm{kHz}, 0.1^{\circ}$ and (E) $300 \mathrm{kHz}, 0.05^{\circ}$ scans. The foliation has $\sim 30 \times 30$ cells, and the joint has $\sim 20 \times 20$ cells, of $\sim 0.1 \mathrm{~m}$ in side. The first column shows surfaces coloured by strike, second column shows surfaces coloured by dip, and third column shows the surfaces' strike and dip histograms. Note that in the second column, the surfaces are coloured with different dip ranges. The foliation is coloured using a $0-30^{\circ}$ dip range, while the joint is coloured using a $60-90^{\circ}$ dip range. The number of measurements is included in the strike histograms. 


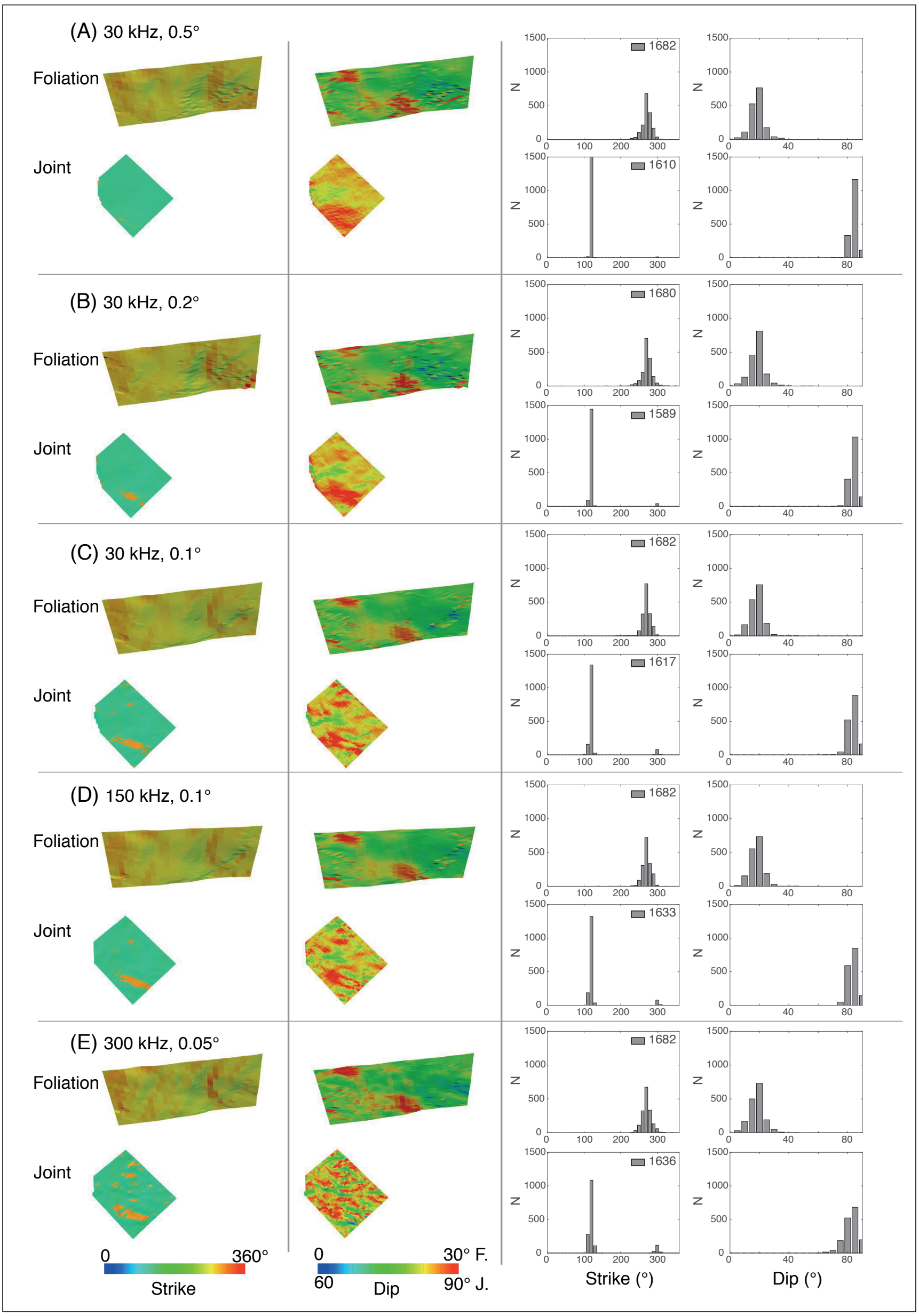




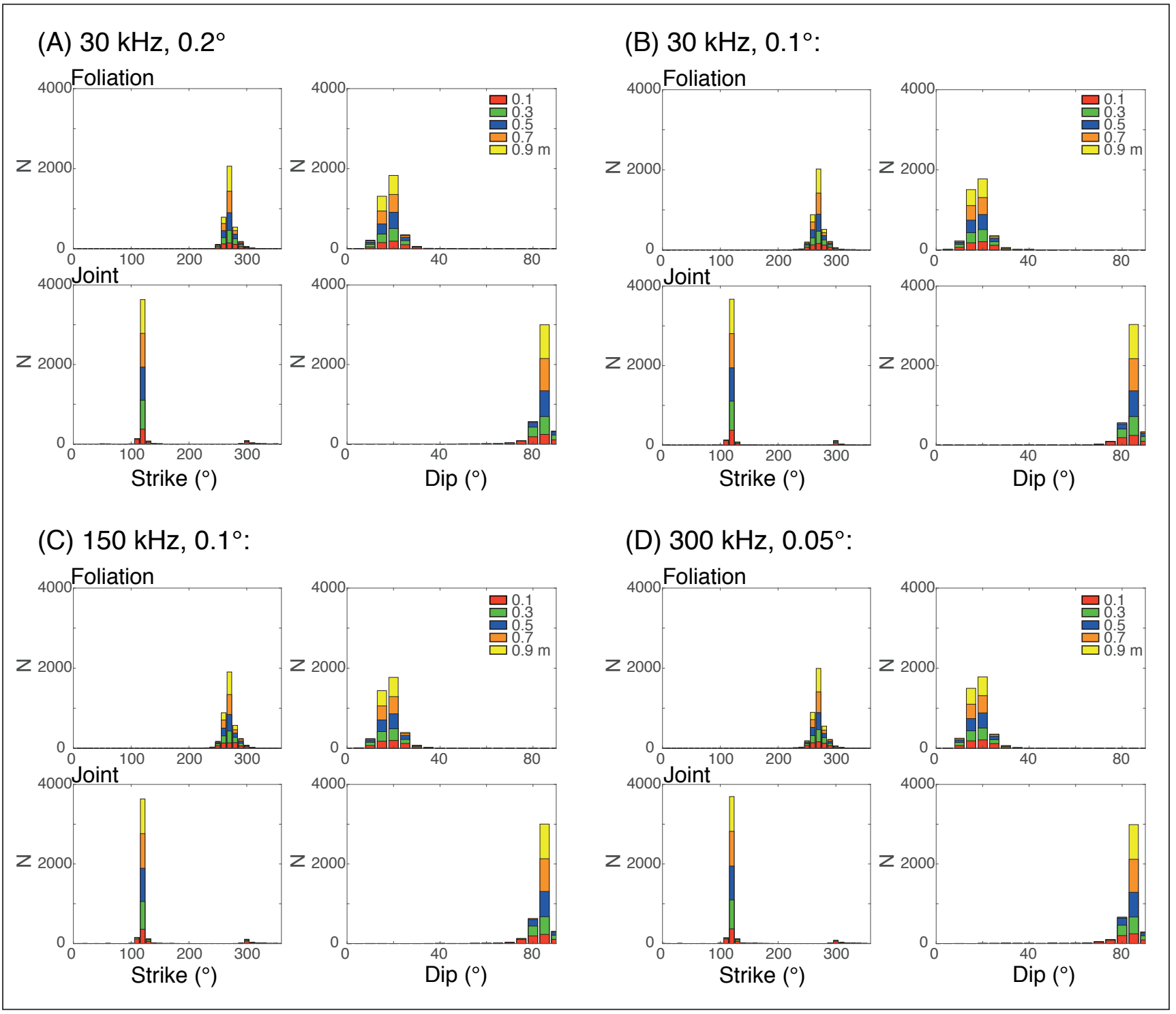

Figure 8. Best-fit to plane, strike and dip histograms of foliation and joint surfaces from the LiDAR (A) $30 \mathrm{kHz}, 0.2^{\circ}$, (B) $30 \mathrm{kHz}, 0.1^{\circ}$, (C) $150 \mathrm{kHz}, 0.1^{\circ}$ and (D) $300 \mathrm{kHz}, 0.05^{\circ}$ scans. Strike and dip are computed at the vertices of the Kriged meshes (Fig. 7) with search radii $r$ of 0.1 (red), 0.3 (green), 0.5 (blue), 0.7 (orange) and 0.9 (yellow) metres.

As the radius $r$ increases, the spread of the computed strike and dip decreases, and for values of $r$ greater than $0.5 \mathrm{~m}$, the distributions are practically the same (Fig. 8), meaning that a $r$ of $\sim 0.5 \mathrm{~m}$ is the optimal sample size for determining the orientation of the plane in this case. Fig. $6 \mathrm{C}$ shows the mean vectors of the poles to the foliation and joint surfaces calculated from this routine with an $r$ of $0.5 \mathrm{~m}$. The mean vectors of all four scans overlap and they are consistent with the compass and smartphone mean vectors (Table 3 ). These mean vectors of the poles to the foliation and joint surfaces of 180/72 and 029/06, respectively, are the best estimates of the orientation for these planes.

\section{Discussion}

As easy as measuring the strike and dip of a plane may look, it is not trivial, especially if dealing with different tools and techniques. A geological compass is the most conventional, sturdy way to take these measurements. Using a good compass like the Brunton Geo compass with a $1^{\circ}$ clinometer scale and good needle damping is a plus. However, such an instrument may not yield good measurements in challenging locations, such as overhangs. The compass mean vector of the poles to the foliation overhang is $\sim 17^{\circ}$ off in trend from our best estimate using the best-fit to plane routine with $r=0.5 \mathrm{~m}$ (Fig. 6C; Table 3).

Smartphone devices have revolutionised the way we take measurements in the field. iPhone devices have a more 
reliable magnetometer than Android devices (e.g., joint plane, Fig. 4; Table 2; Novakova \& Pavlis, 2017), and if, as in Stereonet Mobile, redundant sampling is implemented, they can deliver accurate readings (Allmendinger et al., 2017). The Stereonet Mobile mean vector of the poles to the foliation overhang is very similar to those of the Kriging and best-fit to plane routines $(r=0.5 \mathrm{~m})$ on the LiDAR scans (Figs. 4 \& 6; Tables 2 \& 3). However, if the plane is irregular such as the joint plane, the smartphone may struggle finding an average orientation, even with a large number of measurements (Fig. 4). This is because the size of the phone is smaller than the optimal size to measure the plane. One can bypass this problem by taking sighting measurements at an appropriate distance (Stereonet Mobile has this capability). However, sighting measurements would be difficult to take in awkwardly oriented planes such as overhangs.

The LiDAR scans provide the most precise description of the foliation and joint surfaces. Although Delaunay triangulation is the easiest and often in structural modelling software, the most immediate way to sample these data, blind use of triangulated facets, should be avoided. If the facets are small (i.e., much smaller than the appropriate size to measure the plane), one may end up with a very precise but inaccurate result, especially if the surface is irregular (joint, Figs. 5 \& 6A; Table 3). Kriging and to a greater extent the best-fit to plane routine deliver the most representative results to characterise the planar surfaces (Table 3 ). The bestfit to plane routine also confirms that $\sim 0.5 \mathrm{~m}$ is the optimal size to measure the orientation of the planes, and therefore, sighting measurements are more correct than direct measurements with a compass or a phone on the plane. This 'characteristic' distance is specific to the measured planes, and it will vary according to the geological surface, lithology, resolution of the dataset and scientific aims of the study, among others.

As such, the value of this paper is not providing a specific sampling distance, but rather a methodology to systematically sample the orientation of the plane. A comparison to Cawood et al. (2017) may illustrate the application of our study. These authors compare the accuracy of five different datasets (traditional compass, digital compass, LiDAR, terrestrial SfM, and aerial SfM) on six localities of different orientation along a decametre size syncline. Taking as reference the traditional compass measurements, they observe increasing dispersion of the measurements in the digital compass, aerial SfM, LiDAR and terrestrial SfM. The LiDAR high-density point-cloud preserves the bed asperities and therefore yields a higher dispersion of the measurements. However, according to Cawood et al. (2017), this greater dispersion does not negatively affect the mean orientation of the sampled surfaces, mainly because of the statistical robustness afforded by the LiDAR large sample numbers. This is the case for the gentler, less irregular, overhang foliation of our study, where the different triangulated LiDAR point clouds deliver similar results (Fig. 6A; Table 3). However, it is not the case for the steeper, more irregular joint, where the triangulated LiDAR point clouds deliver very different, inconsistent results (Fig. 6A; Table 3). Large sample numbers and robust statistics deliver precise but not necessarily representative results. The application of the techniques (e.g., best-fit to plane routine) described in this note to datasets, such as those of Cawood et al. (2017), can greatly improve the analysis of these datasets, especially for determining parameters such as fold axes and derived products such as down-plunge projections. This is becoming more important today when virtual outcrop models are more accessible (e.g., open source repositories such as https://www.e-rock.co.uk), and they are actively used in education and research.

Acknowledgements. This note evolved from a Bachelor thesis at the University of Stavanger by Cicilie Trede. Discussions with Richard Allmendinger and reviews by Adam Cawood and Espen Torgersen greatly improved the manuscript. We would like to thank Andreas Habel for his support in the LiDAR surveying. We are grateful to Midland Valley for providing us with an academic licence of Move. The best-fit to plane routine was implemented in Matlab. Stereonets and mean vector calculations were completed in the program Stereonet3D (Cardozo \& Allmendinger, 2013).

\section{References}

Allmendinger, R.W., Cardozo, N. \& Fisher, D.M. 2012: Structural Geology Algorithms: Vectors and Tensors. Cambridge University Press, 289 pp. https://doi.org/10.1017/CBO9780511920202.

Allmendinger, R.W., Siron, C.R. \& Scott, C.P. 2017: Structural data collection with mobile devices: Accuracy, redundancy, and best practices. Journal of Structural Geology 102, 98-112. https://doi.org/10.1016/j.jsg.2017.07.011.

Cardozo, N. \& Allmendinger, R.W. 2013: Spherical projections with OSXStereonet. Computers and Geosciences 51, 193-205. https://doi.org/10.1016/j.cageo.2012.07.021.

Cawood, A.J., Bond, C.E., Howell, J.A. \& Butler, R.W.H. 2017: LiDAR, UAV or compass clinometer? Accuracy, coverage and the effects on structural models. Journal of Structural Geology 98, 67-82. https://doi.org/10.1016/j.jsg.2017.04.004.

Clark, I. \& Harper, W.V. 2000: Practical Geostatistics. Ecosse North Amer Llc, 442 pp.

Feng, Q., Sjögren, P., Stephansson, O. \& Jing, L. 2001: Measuring fracture orientation at exposed rock faces by using a non-reflector total station. Engineering Geology 59, 133-146. https://doi.org/10.1016/S0013-7952(00)00070-3.

Fernandez, O. 2005: Obtaining a best fitting plane through 3D georeferenced data. Journal of Structural Geology 27, 855-858. https://doi.org/10.1016/j.jsg.2004.12.004.

Fisher, N.I., Lewis, T.L. \& Embleton, B.J. 1987: Statistical Analysis of Spherical Data. Cambridge University Press, 329 pp. https://doi.org/10.1017/CBO9780511623059.

Gigli, G. \& Casagli, N. 2011: Semi-automatic extraction of rock mass structural data from high resolution LIDAR point clouds. International Journal of Rock Mechanics and Mining Sciences 48, 187-198. https://doi.org/10.1016/j.ijrmms.2010.11.009.

Guo, J., Liu, S., Zhang, P., Wu, L., Zhou, W. \& Yu, Y. 2017: Towards semiautomatic rock mass discontinuity orientation and set analysis 
from 3D point clouds. Computers \& Geosciences 103, 164-172. https://doi.org/10.1016/j.cageo.2017.03.017.

Hodgetts, D. 2013: Laser scanning and digital outcrop geology in the petroleum industry: A review. Marine and Petroleum Geology 46, 335-354. https://doi.org/10.1016/j.marpetgeo.2013.02.014.

Lee, S., Suh, J. \& Park, H. 2013: Smart Compass-Clinometer: A smartphone application for easy and rapid geological site investigation. Computers \& Geosciences 61, 32-42. https://doi.org/10.1016/j.cageo.2013.07.014.

Novakova, L. \& Pavlis, T.L. 2017: Assessment of the precision of smart phones and tables for measurement of planar orientations: A case study. Journal of Structural Geology 97, 93-103. https://doi.org/10.1016/j.jsg.2017.02.015.

Ramberg, I.B., Bryhni, I., Nøttvedt, A. \& Rangnes, K. 2008: The making of a land: Geology of Norway. Norsk Geologisk Forening, 624 pp.

Riis, F. 2016: Stavanger: Landskapet og geologien. Stavangeren 3, 6-21.

Riquelme, A.J., Abellán, A., Tomás, R. \& Jaboyedoff, M. 2014: A new approach for semi-automatic rock mass joints recognition from $3 \mathrm{D}$ point clouds. Computers \& Geosciences 68, 38-52.

https://doi.org/10.1016/j.cageo.2014.03.014.

Slama, J. \& Pedersen, R.B. 2015: Zircon provenance of SW Caledonian phyllites reveals a distant Timanian sediment source. Journal of the Geological Society 172, 465-478. https://doi.org/10.1144/jgs2014-143.

Thiele, S.T., Grose, L., Samsu, A., Micklethwaite, S., Vollgger, S.A. \& Cruden, A.R. 2017: Rapid, semi-automatic fracture and contact mapping for point clouds, images and geophysical data. Solid Earth 8, 1241-1253. https://doi.org/10.5194/se-8-1241-2017.

Yielding, G. \& Freeman, B. 2016: 3-D seismic-structural workflows examples using the hat creek fault system. In Krantz, B., Ormand, C. \& Freeman, B. (eds.): 3-D Structural Interpretation: Earth, Mind and Machine, American Association of Petroleum Geologists Memoir 111, pp. 155-171. https://doi.org/10.1306/13561991M1111540. 